\title{
Research Paper \\ Effect of One Course Pilates Exercise Program on Serum Levels of Resistin, Vis- fatin, and Chemerin in Overweight Women
}

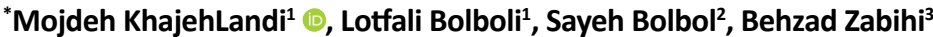

1. Department of Exercise Physiology, Faculty of Educational Sciences and Psychology, University of Mohaghegh Ardabili, Ardabil, Iran 2. Department of Applied Chemistry, Faculty of Basic Sciences, University of Mohaghegh Ardabili, Ardabil, Iran.

3. Department of Sport Management and Biomechanics, Faculty of Educational Sciences and Psychology, University of Mohaghegh Ardabili, Ardabil, Iran.

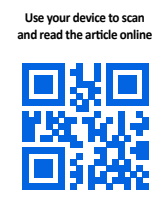

Citation KhajehLandi M, Bolboli L, Bolbol S, Zabihi B. [Effect of One Course Pilates Exercise Program on Serum Levels of Resistin, Visfatin, and Chemerin in Overweight Women (Persian)]. Quarterly of "The Horizon of Medical Sciences". 2021; 27(1):98113. https://doi.org/10.32598/hms.27.1.3004.1

doi'https://doi.org/10.32598/hms.27.1.3004.1

\section{(c) (1) (8)}

Received: 04 Dec 2018 Accepted: 07 Oct 2020 Available Online: 01 Jan 2021

Key words:

Exercise, Resistin, Visfatin, Chemerin, Overweight

\section{A B S T R A C T}

Aims Hemostasis and serum levels of adipokines in the body are affected by physical activity and overweight. The present study investigates the effect of the Pilates exercise program on serum levels of resistin, visfatin, and chemerin in overweight women

Methods \& Materials In this quasi-experimental study, 28 women with overweight voluntarily participated and were randomly divided into two groups of exercise $(n=14)$ and control $(n=14)$. The Pilates exercise program was presented to the exercise group for 8 weeks, 3 sessions per week, while the control group performed no exercise. Blood samples were taken before the intervention and 48 hours after the intervention in a fasting state to measure the serum levels of resistin, visfatin, and chemerin. The t-test was used for intra-group comparison and ANCOVA for inter-group comparison of the variables. The obtained data were analyzed in SPSS V. 23, considering a significance level of $\mathrm{P}<0.05$

Findings After 8 weeks of Pilates exercise, serum levels of resistin $(P=0.001)$, visfatin $(P=0.045)$, and chemerin $(P=0.009)$ decreased significantly compared to pre-test values. A significant reduction in serum levels of resistin $(P=0.005)$, visfatin $(P=0.034)$, and chemerin $(P=0.025)$ were also reported compared to the control group

Conclusion It seems that Pilates exercise can reduce resistin, visfatin, and chemerin levels in overweight women and can be considered as an appropriate exercise program to control the health and physiological conditions of overweight women

\section{Extended Abstract}

\section{Introduction}

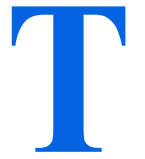

oday, many people in different parts of the world are overweight or obese. This condition is not limited to developed countries [1]. Besides storing energy for a long time, adipose tissue secretes many biological molecules such

as adipokines that control physiological functions, including inflammation, energy homeostasis, and immunity [2]. These adipokines produce important regulators of adipose tissue development and significantly affect glucose metabolism in various body tissues. They are also useful on energy balance at a systematic level [3]. Various adipokines are secreted from adipose tissues, including adiponectin, resistin, retinol-binding protein- 4 , tumor necrosis factor-alpha (TNF- $\alpha$ ), interleukin-2, omentin, chemerin, and visfatin

\section{* Corresponding Author:}

Mojdeh Khajehlandi

Address: Department of Exercise Physiology, Faculty of Educational Sciences and Psychology, University of Mohaghegh Ardabili, Ardabil, Iran Tel: +98 (916) 8262683

E-mail: md.khajehlandi@uma.ac.ir
} 
[4]. Resistin is a peptide hormone whose level is high in obese people. This hormone is closely related to the atherosclerotic lesion, which causes impairment in glucose and lipid metabolisms [5-7]. Studies on the resistin in rats have shown that resistin links obesity to insulin resistance [8].

On the other hand, although obesity has been associated with increased levels of this hormone, some studies have not confirmed this association [9, 10]. Another secreted adipocaine is visfatin, known as pre-B cell colony-enhancing factor or phosphoribosyltransferase [11]. Various studies have reported a positive association between changes in visfatin level and diseases such as obesity, diabetes, and kidney disease [12-14]. Besides, this adipokine is positively associated with insulin resistance [13, 14]. Another studied adipocaine is chemerin, which has an essential role in invoking adipose tissue macrophages and causes inflammation of this tissue [15]. Plasma chemerin concentration is directly related to body mass index (BMI), blood glucose, fasting insulin, leptin, TNF- $\alpha$, and interleukin-6 [16], and its serum level is higher in obese people. By connecting to its receptor, chemerin affects the immune system function [17].

Nowadays, exercise is used as a treatment method for metabolic syndrome, obesity, and insulin resistance [18]. Since changes in the concentration of adipokines are an early sign of reduced and inactive adipose tissue, exercise, and physical activity are crucial for weight loss [19]. Because of the importance of physical activity in the prevention and treatment of many diseases, it is one of the factors that improve vascular function by reducing fat and increasing the insulin sensitivity of tissues. The effect of exercise in different forms has been studied on the levels of resistin, visfatin, and chemerin in human and animal samples. However, conflicting results have been reported. In some studies, a decrease, and in others, no change or increase in their levels has been reported [19-23]. Most studies have used aerobic exercise to lose weight. Still, many people cannot participate in all physical activities because of heart disease, osteoarthritis, low back pain, high blood pressure, obesity, etc. In this regard, Pilates exercises that are performed in a sitting, lying, and standing position without walking or jumping [24] (thus reduce joint injuries) have received more attention.

Regarding the effect of physical activity on serum levels of resistin, visfatin, and chemerin, little research has been conducted in women. It is essential to conduct studies on women as a group in Iran who are more prone to obesity. Because of the few studies on the effect of Pilates on adipokine levels, especially in overweight women, this study aimed to evaluate the impact of a Pilates exercise program on serum levels of resistin, visfatin, and chemerin in overweight women in Iran.

\section{Materials and Methods}

This research is a quasi-experimental study with a pretest-post-test design. The participants were 28 overweight women living in Ahvaz City, Iran, aged 25-35 years with a BMI of $25-29 \mathrm{~kg} / \mathrm{m}^{2}$. They were selected using a purposive sampling method and based on the inclusion criteria (no any cardiovascular and kidney diseases, diabetes, physical and orthopedic injuries, no regular physical activity in the past 6 months, and having the ability to perform sports) and exclusion criteria (taking any medication or supplement, and having no cooperation during the study). All explanations about the study objectives and methods were given to the participants, and they were assured of the confidentiality of their information. They were free to leave the study at any time. Then, they were randomly divided into two groups of exercise $(n=14)$ and control $(n=14)$.

Table 1. The Pilates exercise protocol

\begin{tabular}{|c|c|c|c|}
\hline Type of exercise & Week & Movements & Intensity \\
\hline \multirow[b]{2}{*}{$\begin{array}{l}\text { Exercises on a } \\
\text { mat }\end{array}$} & $1-3$ & $\begin{array}{l}\text { Single-leg hip hinge, half roll down, single leg circle, bending with hands on the ground, leg and } \\
\text { arm kickbacks, mermaid, shoulder bridge, diamond press, cobra, dart, superman, Four limbs bal- } \\
\text { ance with knees bent, single-leg stretch, double-leg stretch, single-leg stretch with spine twist }\end{array}$ & $10-12$ \\
\hline & $4-6$ & $\begin{array}{l}\text { Half roll down, single leg circle, bending with hands on the ground, leg and arm kickbacks, mer- } \\
\text { maid, shoulder bridge, diamond press, cobra with neck rotation, push-up, full star, superman, dart } \\
\text { with rotating the waist to the sides, kenken with legs straight, leaning to the side-lying down, saw, } \\
\text { roll-up, hundred, leg pull, leg pull front, sidekick }\end{array}$ & $12-14$ \\
\hline \multirow[t]{2}{*}{$\begin{array}{c}\text { Exercises with } \\
\text { a ball }\end{array}$} & $7-8$ & $\begin{array}{l}\text { Leg stretch, squat with the ball, single-leg squat with the ball, lifting the feet on the ball, lifting } \\
\text { the chest on the ball with spine twist, feet bridge on the ball, a single-leg bridge on the ball, } \\
\text { backstretch on the ball, leg pull front lifting one leg, push-up on the ball, rolling the ball forward, } \\
\text { bending sideways, hands and legs open, single-leg stretch with the knee bent, single straight leg } \\
\text { stretch, leg pull, hundred, teaser }\end{array}$ & $14-16$ \\
\hline & & $\begin{array}{l}\text { Quarterly of } \\
\text { The Horizon of Medica }\end{array}$ & \\
\hline
\end{tabular}


The exercise program consisted of 8 weeks of Pilates, three 60-minute sessions per week. Each session consisted of three parts: warming up, Pilates exercises, and cooling down. The exercises were first performed on a mat and then using stretch bands and balls (Table 1). The intensity and complexity of movements increased gradually. For warming up and cooling down, the perceived exertion rate of 8-10 was used, and then the rate increased from the first week to the last week. The exercises were conducted first in the standing position and then in sitting and lying positions. The women in the control group did not perform any exercise during this period.

Body height by stadiometer seca, body weight, and BMI through body composition analysis using In body 3 Analyzer, body fat percentage, Waist-to-Hip Ratio (WHR), and biochemical variables were measured first after 12-hour fasting state and before the start of the intervention and then 48 hours after the last session. It is done to avoid the possibility of the acute effect of the previous exercise session on blood variables. The subjects were told not to engage in strenuous activities until 48 hours before starting the first phase of blood sampling. The temperature and time of the first blood sampling were recorded for the next phase after the completion of the protocol. To measure the biochemical variables, 5 $\mathrm{mL}$ of blood was taken from the brachial vein of each subject between 8 and 9 AM. After centrifugation for 10 minutes at $3000 \mathrm{rpm}$, the blood serum was isolated and poured into special microtubes and stored at $-70^{\circ} \mathrm{C}$. An ELISA kit (Cusabio, Biotech Ltd., China) was used with a sensitivity of $0.08 \mathrm{ng}$ / $\mathrm{mL}$ for measuring resistin level, a sensitivity of $7.5 \mathrm{ng} / \mathrm{mL}$ for measuring chemerin level, and a sensitivity of $0.1 \mathrm{ng} /$ $\mathrm{mL}$ for measuring visfatin. Based on the self-report form, the subjects had a normal menstrual period and were not receiving drug treatment during the study period.

The obtained data were analyzed in SPSS V. 23, considering a significance level of $\mathrm{P}<0.05$. Mean, and the standard deviation was used for describing data. After reporting the normality of data distribution using the Shapiro-Wilk test and the equality of variances using Levene's test, the paired t-test and ANCOVA were used to compare intra-group and inter-group variables, respectively.

\section{Results}

Table 2 presents the results related to anthropometric characteristics and body composition of the subjects. No significant differences were observed between the two groups regarding the anthropometric characteristics and body composition at baseline. The intra-group comparison

Table 2. Descriptive statistics and comparison of anthropometric characteristics and body composition in two groups before and after the intervention

\begin{tabular}{|c|c|c|c|c|c|}
\hline \multirow{2}{*}{ Characteristics } & \multirow{2}{*}{ Group } & \multicolumn{2}{|c|}{ Mean \pm SD } & \multicolumn{2}{|c|}{$\mathbf{P}$} \\
\hline & & Pre-test & Post-test & Inter-group & Intra-group \\
\hline \multirow{2}{*}{ Age (y) } & Control & $30.1 \pm 4.0$ & & & \\
\hline & Experiment & $29.6 \pm 3.4$ & & & \\
\hline \multirow{2}{*}{ Height (cm) } & Control & $165.5 \pm 4.0$ & & & \\
\hline & Experiment & $165.7 \pm 3.3$ & & & \\
\hline \multirow{2}{*}{ Weight (kg) } & Control & $74.6 \pm 3.4$ & $73.8 \pm 4.1$ & 0.093 & \multirow{2}{*}{$0.003^{\#}$} \\
\hline & Experiment & $77.1 \pm 3.2$ & $74.9 \pm 3.3$ & $0.004^{*}$ & \\
\hline \multirow{2}{*}{ Body mass index $\left(\mathrm{kg} / \mathrm{m}^{2}\right)$} & Control & $26.5 \pm 0.9$ & $26.8 \pm 1.1$ & 0.96 & \multirow{2}{*}{$0.005^{\#}$} \\
\hline & Experiment & $28.0 \pm 0.8$ & $27.5 \pm 1.1$ & $0.005^{*}$ & \\
\hline \multirow[b]{2}{*}{ Body fat percentage } & Control & $36.36 \pm 4.22$ & $36.10 \pm 5.24$ & 0.987 & \multirow{2}{*}{$0.008^{*}$} \\
\hline & Experiment & $39.45 \pm 3.35$ & $34.92 \pm 1.46$ & $0.030^{*}$ & \\
\hline \multirow{2}{*}{ Waist-to-hip ratio } & Control & $0.96 \pm 0.02$ & $0.98 \pm 0.05$ & 0.094 & \multirow{2}{*}{$0.002^{\#}$} \\
\hline & Experiment & $0.95 \pm 0.05$ & $0.91 \pm 0.08$ & $0.010^{*}$ & \\
\hline
\end{tabular}


Table 3. Descriptive statistics and inter-group and intera-group comparison of resistin, visfatin, and chemerin levels in two groups before and after the intervention

\begin{tabular}{|c|c|c|c|c|c|}
\hline \multirow{2}{*}{ Variables } & \multirow{2}{*}{ Group } & \multicolumn{2}{|c|}{ Mean \pm SD } & \multicolumn{2}{|c|}{$\mathbf{P}$} \\
\hline & & Pre-test & Post-test & Inter-group & Intra-group \\
\hline \multirow[b]{2}{*}{ Resistin (ng/mL) } & Control & $6.14 \pm 6.14$ & $6.07 \pm 0.31$ & 0.654 & \multirow[b]{2}{*}{$0.005^{\circ}$} \\
\hline & Experiment & $6.37 \pm 0.26$ & $4.85 \pm 0.19$ & & \\
\hline \multirow[b]{2}{*}{ Visfatin (ng/mL) } & Control & $1.23 \pm 1.10$ & $1.31 \pm 0.17$ & 0.146 & \multirow[b]{2}{*}{$0.034^{*}$} \\
\hline & Experiment & $1.33 \pm 1.11$ & $0.91 \pm 0.30$ & $0.045^{*}$ & \\
\hline \multirow[b]{2}{*}{ Chemerin (ng/ml) } & Control & $1100.15 \pm 3.08$ & $1068.07 \pm 4.35$ & 0.700 & \multirow[b]{2}{*}{$0.025^{*}$} \\
\hline & Experiment & $1009.83 \pm 3.39$ & $780.08 \pm 3.84$ & $0.009^{*}$ & \\
\hline
\end{tabular}

showed that the mean weight $(\mathrm{P}=0.004)$, $\mathrm{BMI}(\mathrm{P}=0.005)$, fat percentage $(\mathrm{P}=0.030)$, and WHR $(\mathrm{P}=0.010)$ decreased significantly after the intervention in the exercise group compared to controls. The inter-group comparison also showed that the mean weight $(\mathrm{P}=0.003)$, BMI $(\mathrm{P}=0.005)$, fat percentage $(\mathrm{P}=0.008)$, and $\mathrm{WHR}(\mathrm{P}=0.002)$ decreased significantly after the intervention in the exercise group compared to controls.

As shown in Table 3, the results of the paired t-test showed a significant intra-group difference. They indicated that 8 weeks of Pilates exercise significantly reduced serum levels of resistin $(\mathrm{P}=0.001)$, visfatin $(\mathrm{P}=0.045)$, and chemerin $(\mathrm{P}=0.009)$. The results of ANCOVA showed a significant inter-group difference and indicated that 8 weeks of Pilates exercise significantly reduced serum levels of resistin $(\mathrm{P}=0.005)$, visfatin $(\mathrm{P}=0.034)$, and chemerin $(\mathrm{P}=0.025)$. There was also a significant decrease in insulin level in the exercise group after the intervention (Figure 1).

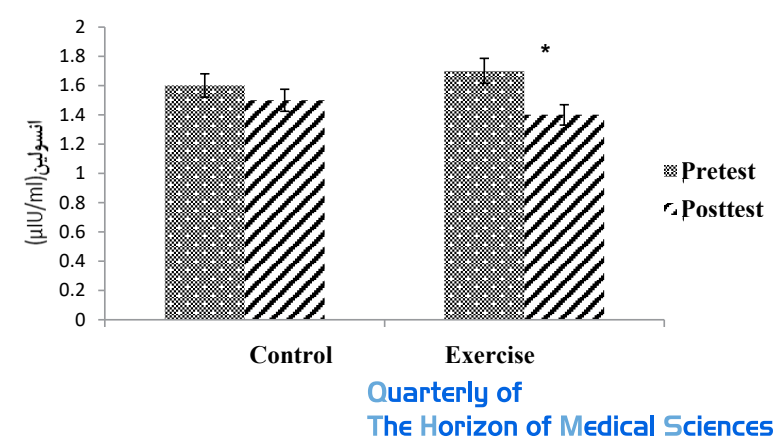

Figure 1. Comparing insulin level in two groups before and after the intervention

* Significant difference between groups.

\section{Discussion}

There is ample evidence that some hormones secreted by adipose tissue are involved in adipogenesis, energy metabolism, and inflammation [25-29]. Previous studies have reported the effect of exercise on the adipokines: resistin, visfatin, and chemerin [26-30]. The purpose of this clinical trial was to evaluate the impact of the Pilates exercise program on serum levels of resistin, visfatin, and chemerin in overweight women. The findings showed that the serum levels of all three adipokines were significantly reduced after the intervention. According to recent studies, resistin has been reported as a secretor of many proteins and is a new signal molecule that is reduced during adipogenesis [31]. In contrast to several studies in which the resistance levels increased or remained unchanged, its levels in the present study decreased significantly. Changes in weight and fat percentage are suggested as possible mechanisms to reduce resistin levels after exercise [26]. The result of the present study regarding the effect of exercise on resistin level and its reduction is consistent with the results of Sartor et al. [27], Gueugnon et al. [28], and Gorge et al. [29]. Still, it is against the findings of Jones et al. [30] and Kang et al. [31]. The decrease in body fat percentage and the decrease in serum level of resistin may be related to the body's physiology in response to the type and duration of exercise [24]. In the study by Jones et al. [30], who examined the effect of 16 weeks of aerobic exercise with an intensity of 50\%-85\% maximum oxygen consumption, no weight loss was observed, but a decrease in body fat percentage was reported. To influence the body fat percentage, the intensity and duration of exercise should be considered so that fatty acids are used as a source of energy. The discrepancy between results may be the difference in duration/intensity/type of exercise and gender [24], which are factors affecting the production of resistin. 
Another adipokine measured in the present study was visfatin, whose serum levels decreased after 8 weeks of Pilates exercise. Although the function of visfatin has not yet been fully elucidated, it may play a dual role. The first is the autocrine/paracrine function that facilitates the differentiation of fat cells into visceral adipose tissue [32]. Another issue is the endocrine role, which affects insulin sensitivity in peripheral tissues and glucose, and is thus involved in the development of obesity $[32,33]$. In our study, the serum level of insulin also decreased after 8 weeks of Pilates exercise. One of the reasons for this decrease is the increase in insulin sensitivity, which reduces serum levels. Many studies have shown that physical activity reduces the serum level of visfatin [34-36]. For example, Haider et al. examined the effect of aerobic exercise on visfatin levels in 18 patients with type 1 diabetes. The exercise was performed on an ergometer exercise bike with an intensity of $60 \%-70 \%$ heart rate reserve for 2-4 months, each session for 1 hour. After exercise, visfatin levels in the experimental group decreased significantly, and this effect remained stable for 8 months after the end of the program [34]. Another study compared the effects of 8 weeks of strength and endurance training ( 8 weeks, 3 sessions per week) on plasma visfatin levels in middle-aged men. It showed that both strength and endurance trainings reduce plasma visfatin concentration in middle-aged men by lowering body fat percentage [35], which is consistent with our study. Plasma reduction of visfatin due to exercise is probably due to weight loss and body composition changes of overweight women. It can be said that the decreased visfatin occurs after long-term exercise (8-12 weeks), which is not affected by gender or age. However, in the study by Taghian et al. [37], 12 weeks of aerobic exercise had no significant effect on serum levels of visfatin in obese women. This discrepancy may be due to differences in the exercise protocol, study population, duration and intensity of exercise, nutrition, age, race, etc. In general, long-term exercise with a specific intensity, such as Pilates, can alter visfatin levels and play a useful role in controlling overweight and obesity.

Another biochemical factor measured in the present study was chemerin, whose level decreased significantly after 8 weeks of Pilates exercise. In a study on patients undergoing weight loss after surgery, serum chemerin levels significantly reduced after surgery, suggesting that it may mediate metabolic changes in obesity [38]. Experimental evidence indicates that reduced chemerin level or its receptor disrupts fat cell differentiation and alters the expression of vital genes involved in fat and glucose metabolism. Reports have also suggested an additional role for chemerin in various biological processes, including cell differentiation and proliferation, angiogenesis, renal function, and energy metabolism [39]. Studies have shown that serum chemerin levels increase in obese people compared to lean people. Chemerin circulation levels positively correlate with inflammatory markers such as TNF- $\alpha$, interleukin- 6 , and C-reactive protein $[40,41]$. Another study on 36 women with diabetes showed that the plasma levels of chemerin decreased significantly [41]. Another study on 35 overweight people with diabetes, 12 weeks of exercise also reduced serum chemerin levels. They showed that changes in chemerin concentration during 12 weeks were negatively associated with insulin sensitivity and positively correlated with changes in fasting blood sugar and total cholesterol [42]. This decrease in chemerin level in the mentioned studies is consistent with the results of the present study. However, in some studies, an increase in the chemerin level has been reported. For example, Chakaroun et al. in a study on the effect of 12 weeks of exercise (20-min warm-up, 20-min swimming, and 20-min cooling down) on obese people with type 2 diabetes, reported that the chemerin mRNA expression level was higher, especially in adipose tissue and correlated with circulating chemerin, BMI, body fat percentage, C-reactive protein, homeostasis model assessment of insulin resistance, and glucose infusion rate. This increase may be due to insulin resistance in these patients. The increase in mRNA supports the role of chemerin in increasing the mRNA in adipose tissue of obese people with type 2 diabetes [23], which is against our results. The reasons for this discrepancy are the duration of exercise and the patients' medical history.

It should be noted that chemerin response to exercise is influenced by various factors, especially when comparing subjects with different diseases. It seems that when the intensity of exercise is low, the chemerin level increases, but when the intensity of exercise is moderate or high, its level decreases. Some of the limitations of this study were different adaptive responses of women to the exercises, their individual differences, and dietary. Therefore, coaches and sports professionals are advised to design training protocols more carefully.

\section{Conclusion}

Eight weeks of Pilates exercise improves anthropometric parameters and significantly reduces the resistin, visfatin, and chemerin levels in inactive, overweight women. Pilates can have an impact on metabolic status through increasing vagus nerve stimulation, reducing inflammatory cytokines (which play an essential role in chronic diseases), visceral fat, and oxidative stress, and improving insulin sensitivity. Perhaps one reason for these changes is the duration of exercise and reduced weight and BMI of women after Pilates. However, due to the lack of control over some factors such 
as nutrition and motivation, these results should be interpreted cautiously.

\section{Ethical Considerations}

Compliance with ethical guidelines

This study has been approved by the Ethics Committee of Ardabil University of Medical Sciences (Code: IR.ARUMS.REC.1398.114). It has a clinical trial Code IRCT20181203037718N1.

\section{Funding}

This research did not receive any grant from funding agencies in the public, commercial, or non-profit sectors.

\section{Authors' contributions}

Conceptualization and supervision: Mojdeh Khajehlandi and Lotfali Bolboli; Methodology: Mojdeh Khajehlandi; Investigation, writing original draft, and writing review \& editing, funding acquisition and resources: All authors; Data collection: Mojdeh Khajehlandi and Behzad Zabihi; Data analysis: Sayeh Bolbol.

\section{Conflicts of interest}

The authors declared no conflict of interest. 
This Page Intentionally Left Blank 


\title{
بررسى تأثير يك دوره تمرين ورزشى ييالاتس بر سطوح سرمى رزيستين، ويسفاتين، و كمرين

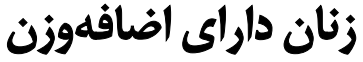

\author{
"مرده خواجهلندى' ـه، لطفعلى بلبلى'، سايه بلبل'، بهزاد ذبيحى' \\ 1. كروه فيزيولوزي ورزشى، دانشكده علوم تربيتى و روانشناسى، دانشعاه محقق اردبيلى، اردبيل، ايران.

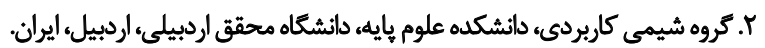

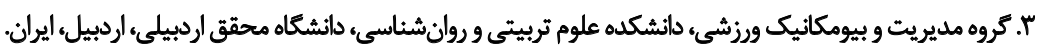

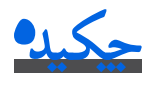

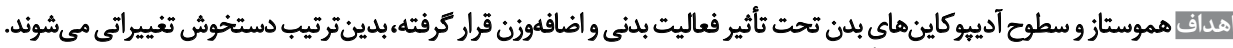

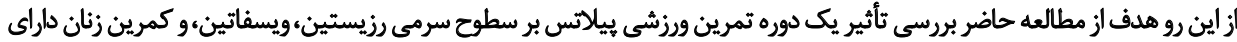

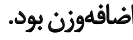

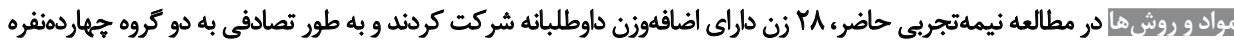

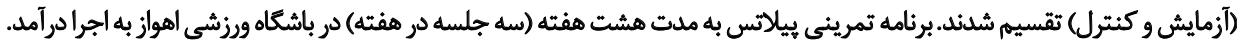

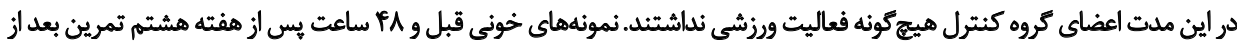

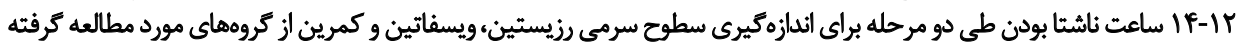

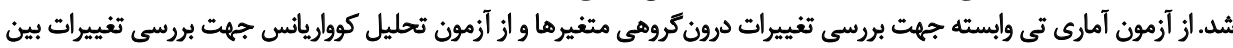

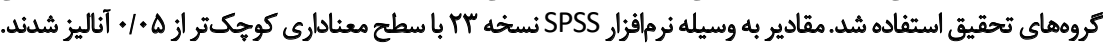

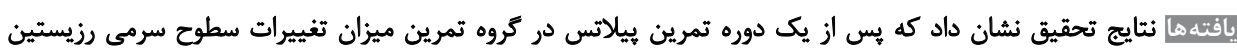

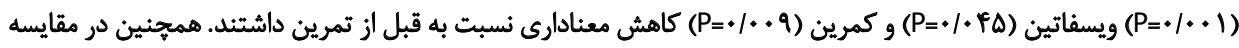

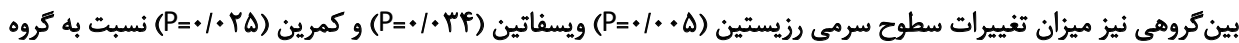
كنترل كاهش معناداري داشتئد.

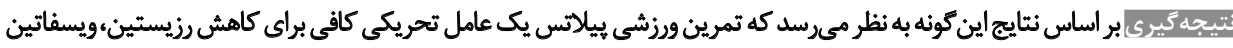

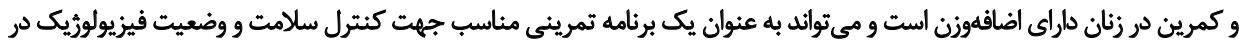

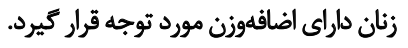

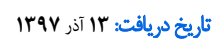

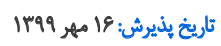

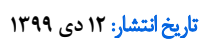

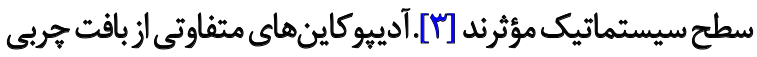

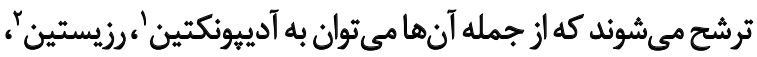

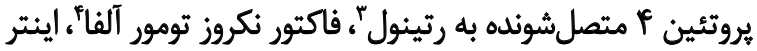

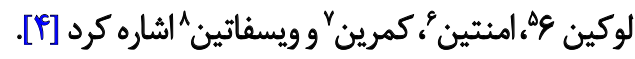

1. Adiponectin

2. Resistin

3. Retinol binding protein-4

4. Tumor necrosis factor alpha

5. Interleukin-2

6. Omentin

7. Chemerin

8. Visfatin

do.to

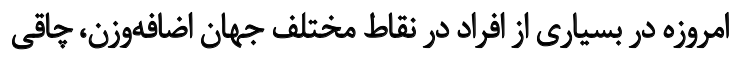

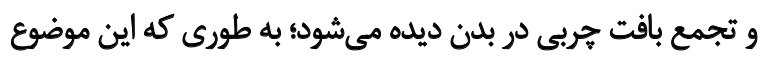

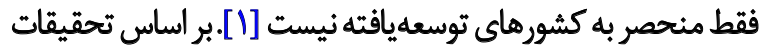

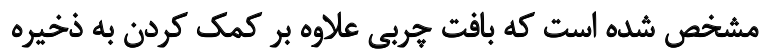

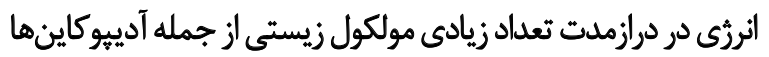

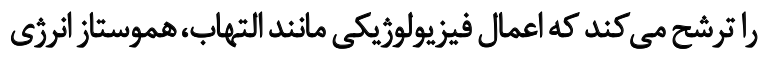

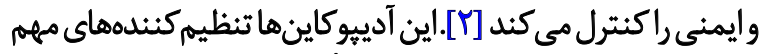

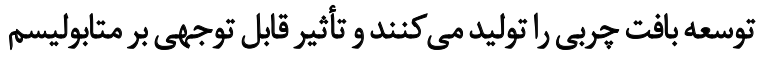

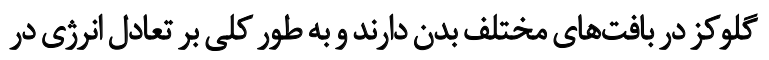


اين اساس با توجه به اينكه تمرينات ييلاتس در حالت نشسته،

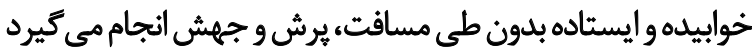

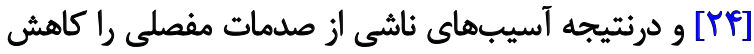

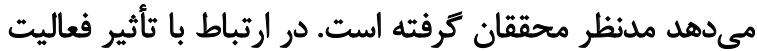

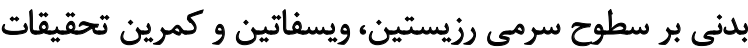

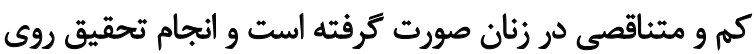

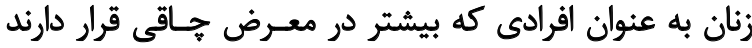

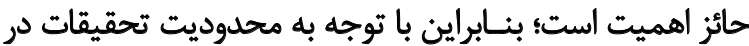

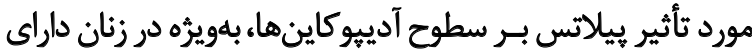

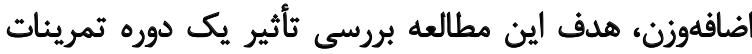
ورزشى بيلاتس بر سطوح سرمى رزيستين، ويسفاتين و كمرين باتين

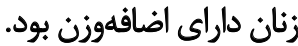

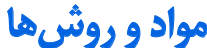

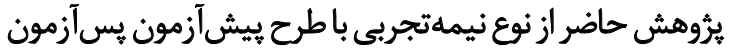

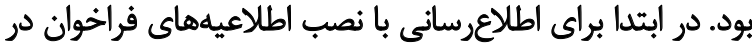

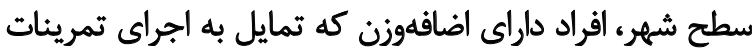

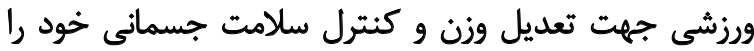

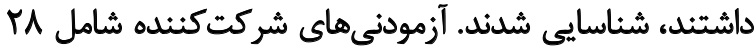

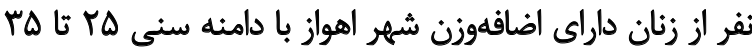

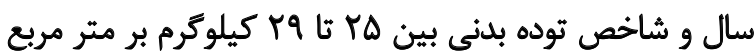

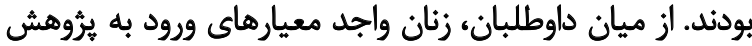

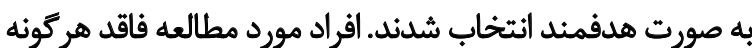

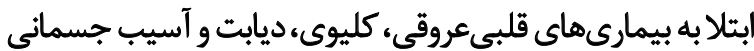

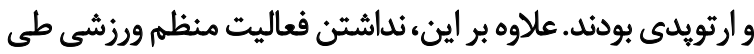

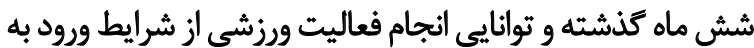

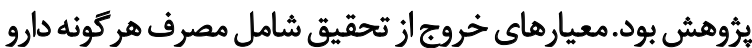

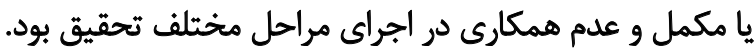

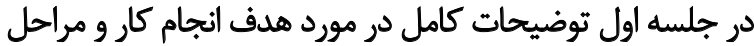

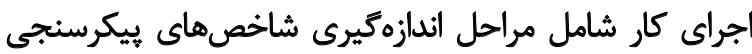

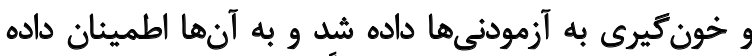

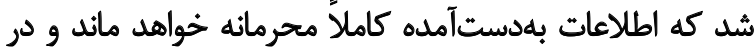

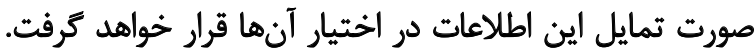

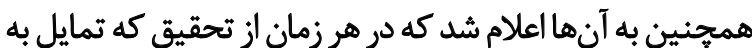

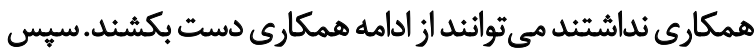

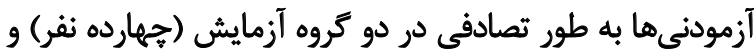
كروه كنترل (جهارده نفر) قرار ترفتيند.

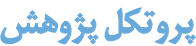

برنامه تمرينى شامل هشت هفته تمرين ييلاتس (سه جلسه در

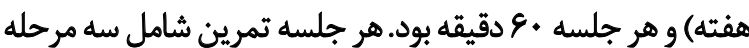

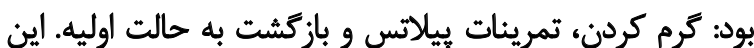

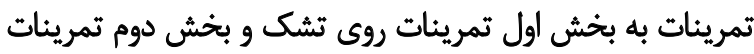

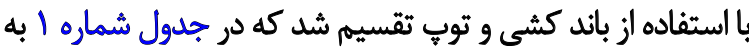

رزيستين هورمون بيتيدى است كه سطح آن در افراد هاق

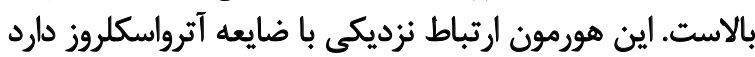

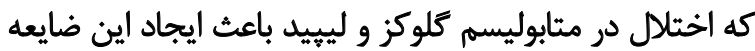

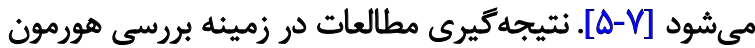

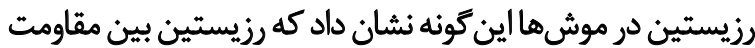

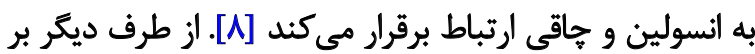

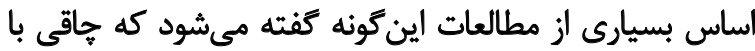

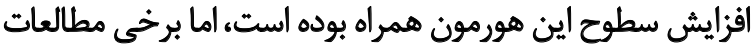

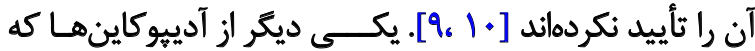

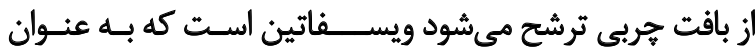

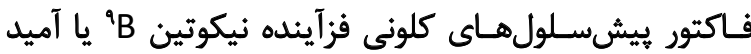

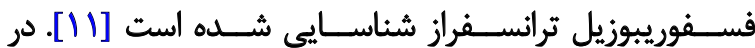
تحقيقات مختلف ارتباط مثبت بين تغييرات سطور

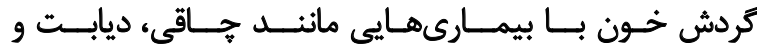

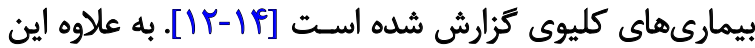

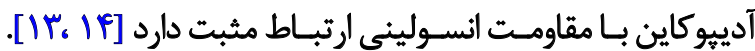

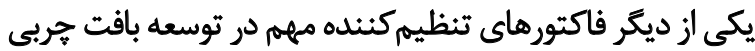

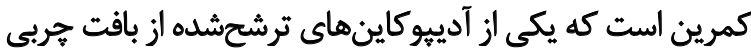

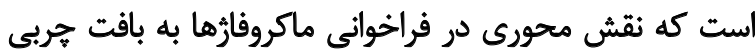

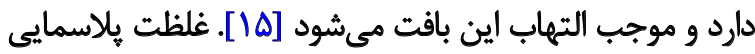

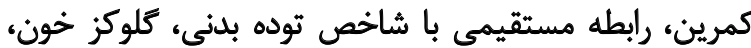

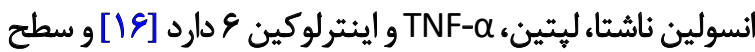

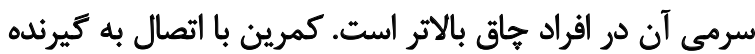

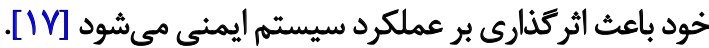
امروزه از ورزش به عنوان روش كمكدرمانى براى سندرم

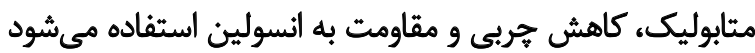

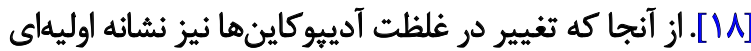

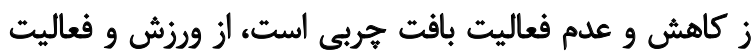

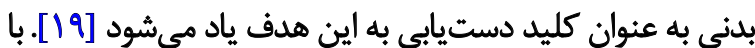

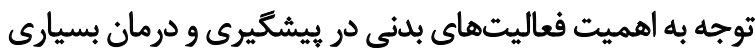

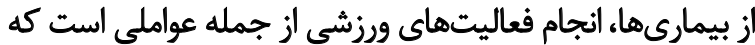

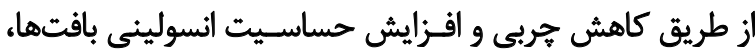

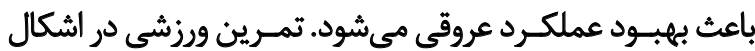

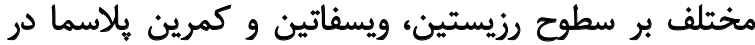

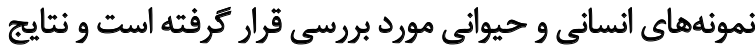

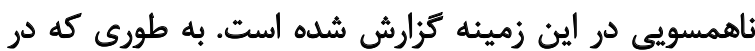

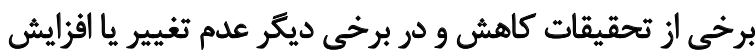

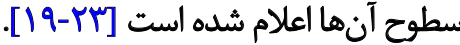

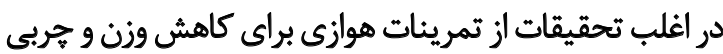

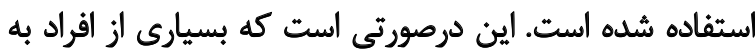

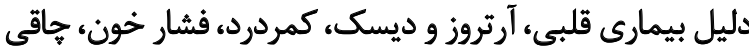

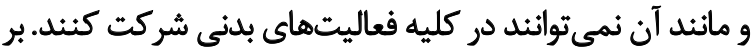

9. Factor -PBEF Enhancing Colony Pre B cell 
جدول ا. نمايش افزايش شدت، مدت و نوع تمرينات اصلى در هفتههاى متوالى يروتكل تحقيق

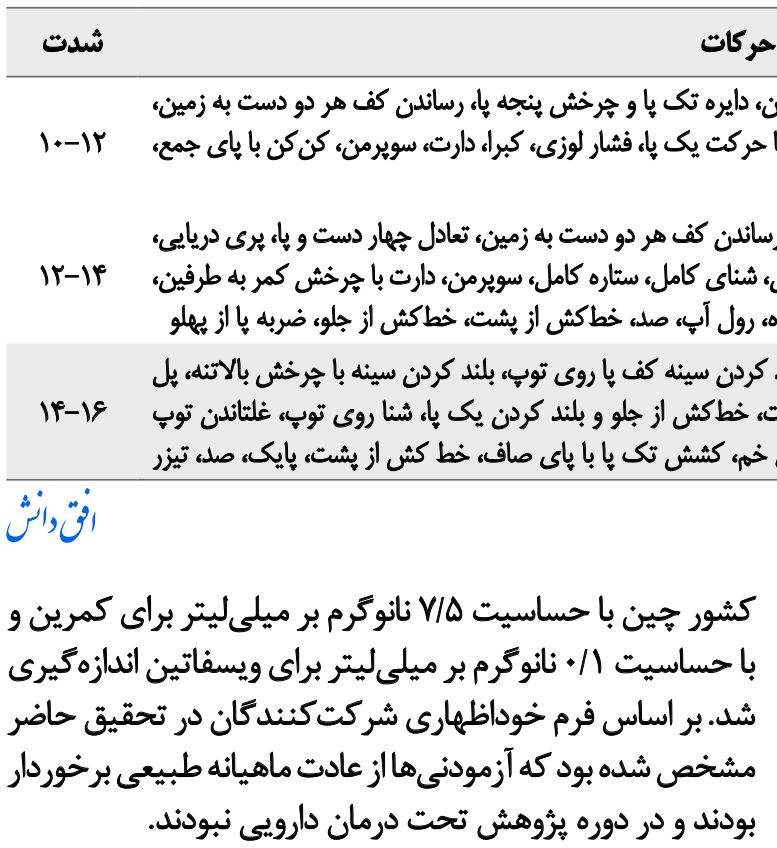

تثاليل آمارى

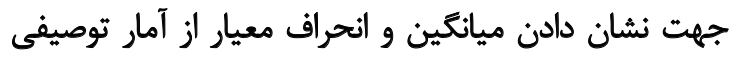

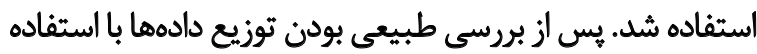

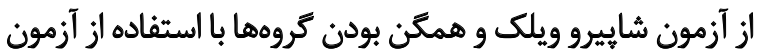

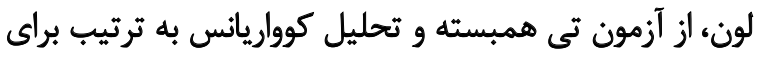

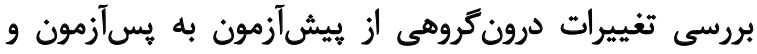

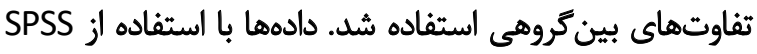

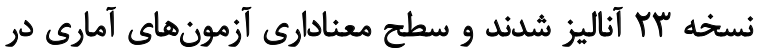
سطح ه • P Pعريف شد.

bevile

در جدول شماره Y يافتههاى مربوط به شاخصهاي

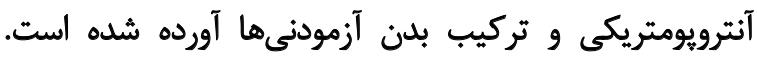

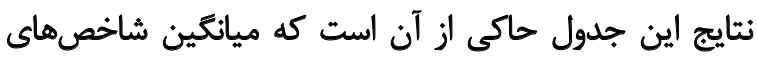

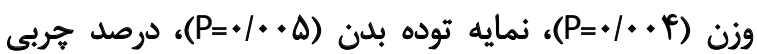

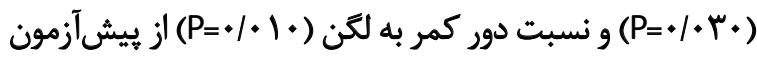

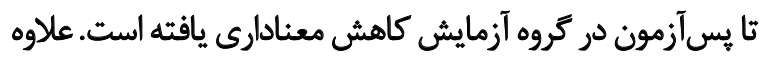

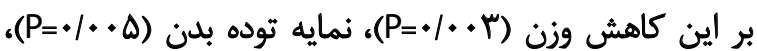

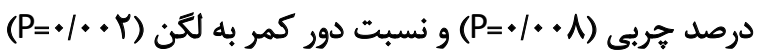

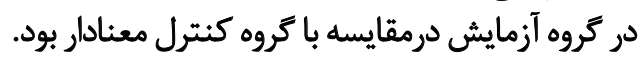

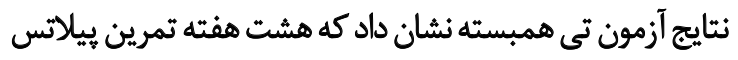

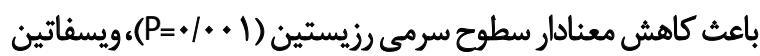

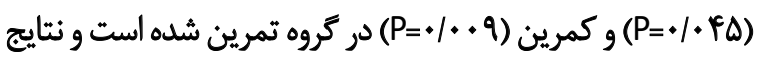

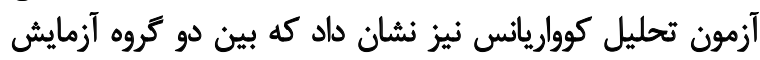

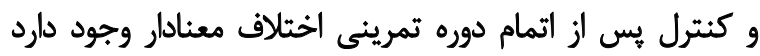

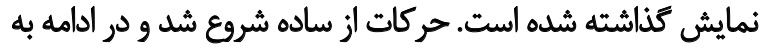

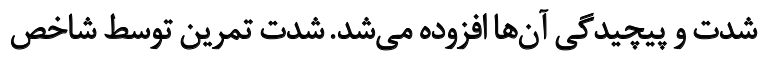

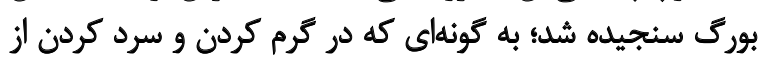

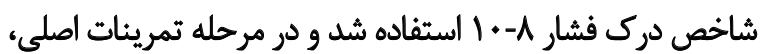

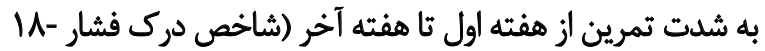

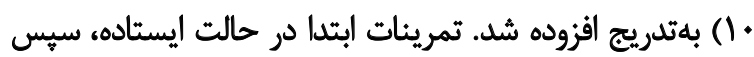

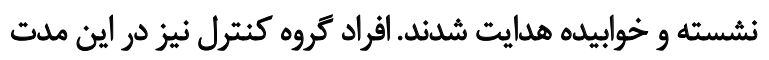
هيج كونه فعاليت ورزشي نداشيتئد.

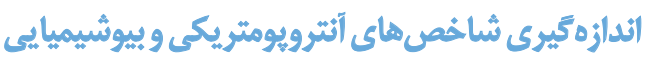

شاخصهاى قد (قدسنج Seca)، وزن، شاخص توده بدن

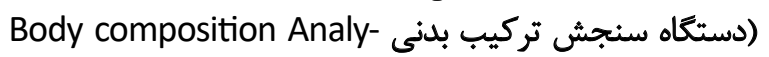
Ser, in body 3

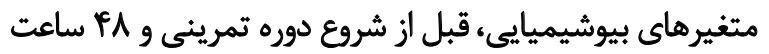

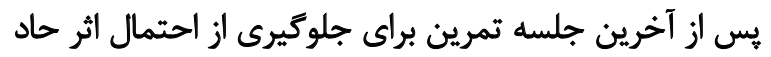

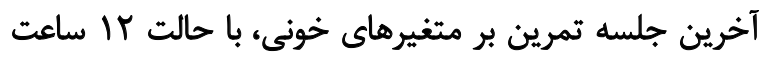

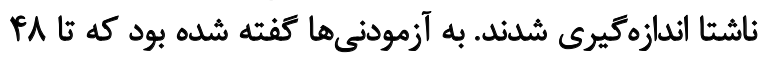

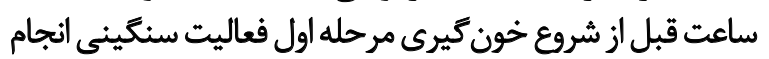

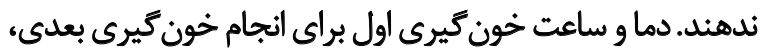
بعد از اتمام يروتكل ثبت شد. بر اساس آزمون توصيفى مشخص آند

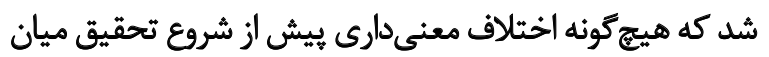

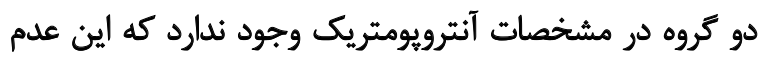

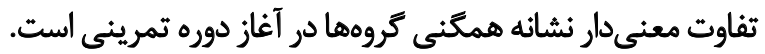

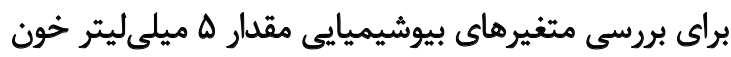

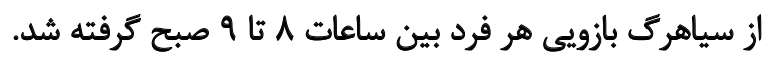

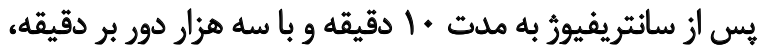

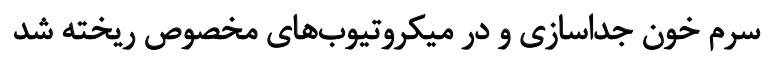

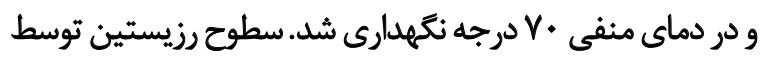
كيت آزمايشكاهى

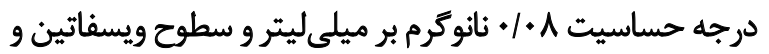

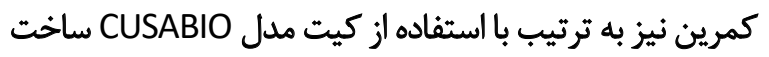


جدول r. شاخصهاى آنترويومتريكى و تركيب بدنى كروه آزمايش و كنترل

\begin{tabular}{|c|c|c|c|c|c|}
\hline \multicolumn{2}{|c|}{$\mathbf{P}$} & \multicolumn{2}{|c|}{ ميانكين =انحراف معيار } & \multirow{2}{*}{ 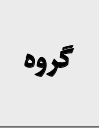 } & \multirow{2}{*}{ شاخص } \\
\hline \multirow[t]{5}{*}{ بين كروهى } & درون كروهى & يس آزمون & ييش آزمون & & \\
\hline & & & $r \cdot / \Lambda \pm \%$ & كتثرل & \multirow{2}{*}{ سن (سال) } \\
\hline & & & $r q / g \pm r / 4$ & آزمايش & \\
\hline & & & $18 \Delta / \Delta \pm+\%$ & كنترل & \multirow{2}{*}{ قد (ساتتىمتر) } \\
\hline & & & $\mid \varepsilon \Delta / V \pm T / T$ & أزمايش & \\
\hline \multirow[t]{2}{*}{$\%$} & .1 .94 & $n / A \pm \varphi / 1$ & $n e / \varepsilon \pm r / \varphi$ & كثترل & \multirow{2}{*}{ وزن (كيلوكرم) } \\
\hline &.$/ . p \varphi$ & $n / q \pm r / r$ & $W / \pm \pm r / T$ & آزمايش & \\
\hline \multirow[t]{2}{*}{.$\bullet \Delta *$} &.$/ Q$ & $r \varepsilon / A \pm 1 / 1$ & $r q / \Delta \pm . / q$ & كتترل & \multirow{2}{*}{ (كيلوكرم بر متر مربع) } \\
\hline & $1 \cdot \cdot \Delta^{*}$ & $T V / \Delta \pm V / 1$ & $Y N \cdot \pm \cdot / \Lambda$ & آزمايش & \\
\hline \multirow[t]{2}{*}{$\% \cdot \cdot A *$} & ./ur & $r \& / 1 \cdot \pm \Delta / \pi r$ & $r \& / R E \pm F / M r$ & كتترل & \multirow{2}{*}{ هربيى بدن (درصد) } \\
\hline & $.1 . \%+*$ & $\Gamma \varphi / q \Upsilon \pm 1 / \uparrow \varepsilon$ & $\Gamma q / F \Delta \pm \Gamma / T \Delta$ & آزمايش & \\
\hline \multirow[t]{2}{*}{$\%$ \%* } & .1 .94 & $\cdot / 4 \pm \cdot / \cdot \Delta$ & $. / Q 8 \pm . / .5$ & كتترل & \multirow{2}{*}{$\begin{array}{c}\text { نسبت دور كمر به لكن } \\
\text { (WHR) }\end{array}$} \\
\hline & $.1 .10^{\circ}$ & $\cdot / 91 \pm \cdot 1 \cdot 1$ & $. / 9 \Delta \pm . / \bullet \Delta$ & آزمايش & \\
\hline
\end{tabular}

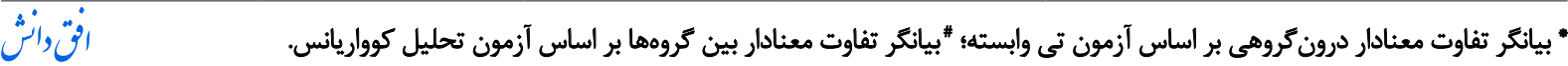

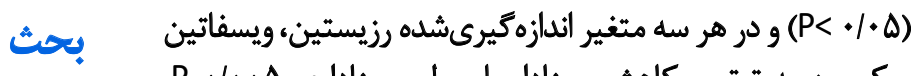

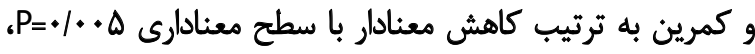

شواهل علمى بسيارى نشان مى دهند كه برخى از هورمونهاي

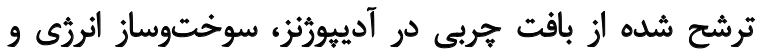

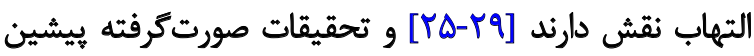

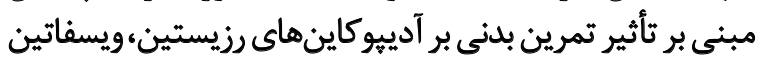

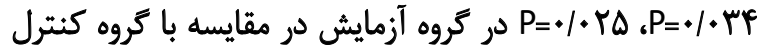

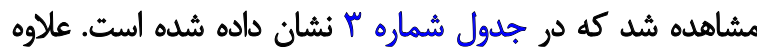

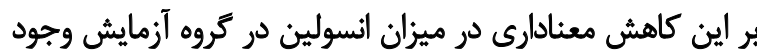

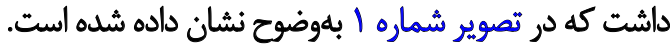

جدول با. متغيرهاى تحقيق ييش و بس از هشت هفته تمرين ييلاتس در كروه آزمايش و كروه كنترل و مقايسه درون كروهى و بين كروهى آنها

\begin{tabular}{|c|c|c|c|c|c|}
\hline \multicolumn{2}{|c|}{$\mathbf{P}$} & \multicolumn{2}{|c|}{ ميانكين |تحراف معيار } & \multirow{2}{*}{ ك كروه } & \multirow{2}{*}{ متغير } \\
\hline بين كروهى & درون كروهى & يس آزمون & ي يششآزمون & & \\
\hline \multirow{2}{*}{$\% \cdot \Delta^{\#}$} &.$/ 9 \Delta P$ & $91 \cdot V \pm \cdot / N 1$ & $9 / N \pm . / r$. & كتترل & \multirow{2}{*}{ رزيستين } \\
\hline &.. $.1^{\circ}$ & $\varphi / / \Delta \pm . / / q$ & $g / R V \pm . / R Q$ & آزمايش & \\
\hline \multirow{2}{*}{$\% \cdot \mu \mu^{*}$} & & $|/ r| \pm \cdot / Y$ & $1 / T r \pm \cdot / 1$. & كثترل & \multirow{2}{*}{$\begin{array}{l}\text { يسفاتين } \\
\text { ng/m }\end{array}$} \\
\hline & $.1 . \% 0^{\circ}$ & $. / 91 \pm+/ \pi$ & $1 / T r \pm+/ 11$ & آزمايش & \\
\hline \multirow{2}{*}{$1 \cdot r \Delta^{*}$} & $\cdot / V \cdot$. & $1 . \& N \cdot V \pm F / \% \Delta$ & $11+\cdot / 1 \Delta \pm r / \cdot \Lambda$ & كنترل & \multirow{2}{*}{ كمرين } \\
\hline & $\%$ & $V A \cdot / \cdot A \pm r / A r$ & $1 . .9 / A r \pm \Psi r / 99$ & آزمايش & \\
\hline
\end{tabular}

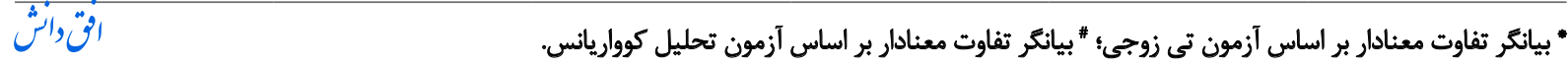




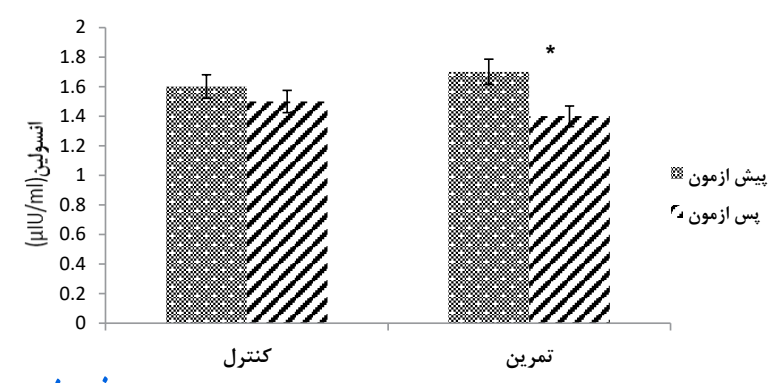

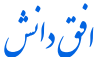

تصوير ا. ميزان ثغييرات انسولين قبل و بعد از هشت هفته تمرين بيلاتس "نشاندهنده تفاوت معنادار بين كروهها.

آن است كه حساسيت انسولين رادر بافتهاي محيطى و بنابر بائراين

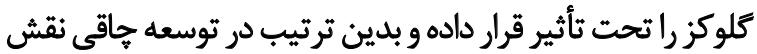

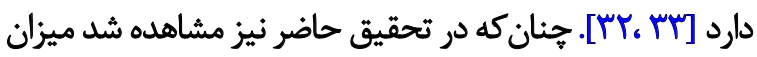
انسولين سرمى كاهش يافت. شايد يكى از دلايل كاهش إنس انسولين

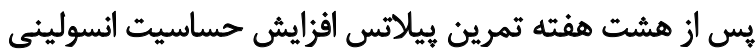

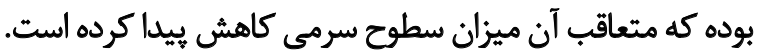

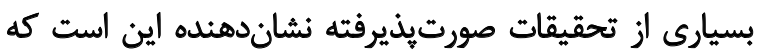

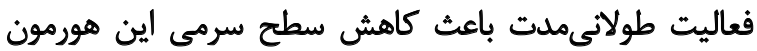

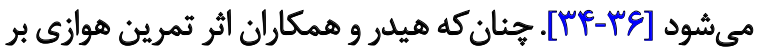

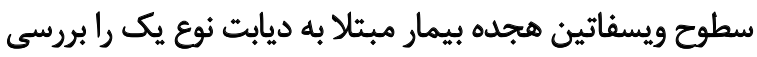

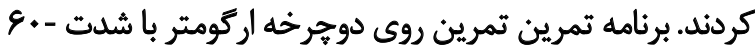

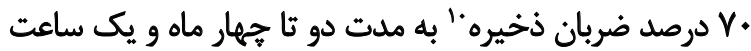

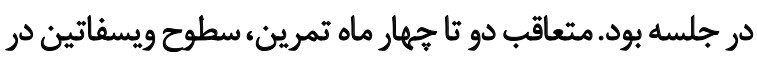

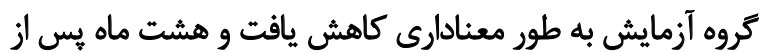

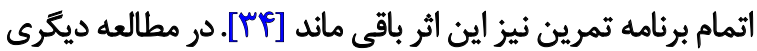

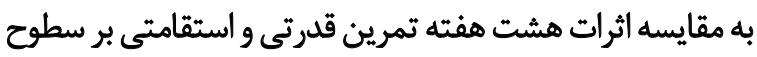

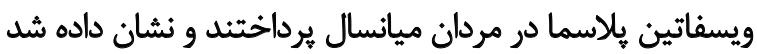

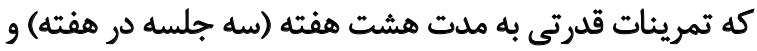

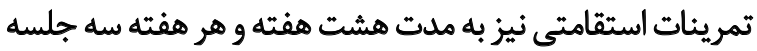

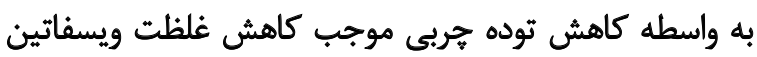

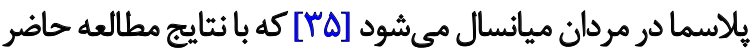

همسو هستئد.

با توجه به نتايج تحقيق حاضر و كاهش وزن آزمودنى ها بـ فيس

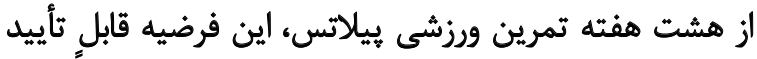

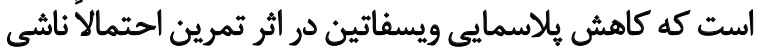

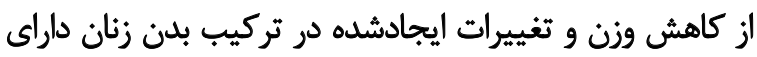

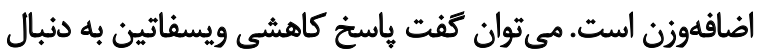

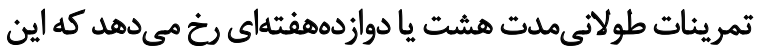

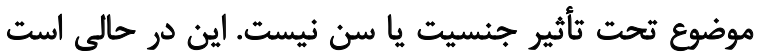

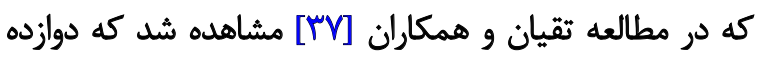

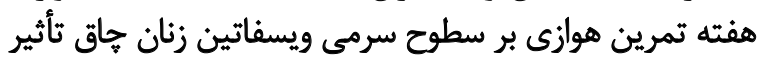

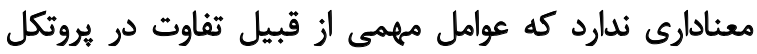

10. Heart Rate Recovery (HRR)
و كمرين هستند [•r-ب_r]]. هدف از مطالعه حاضر بررسى تأثير

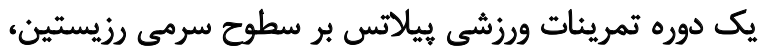

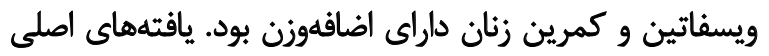

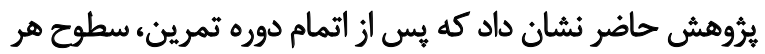

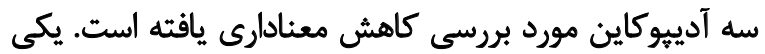

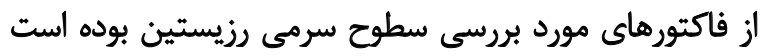

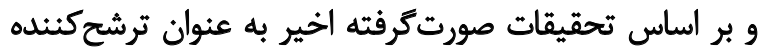

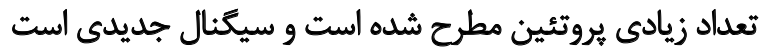

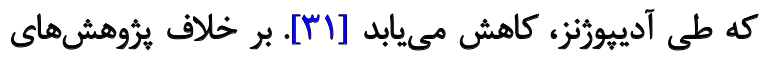

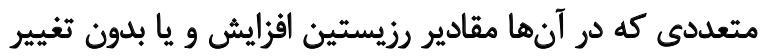

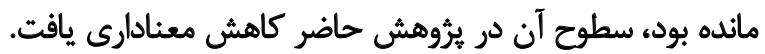

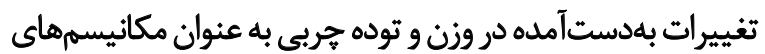

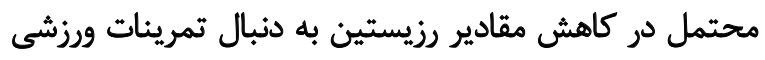

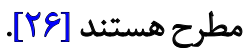

نتيجه مطالعه حاضر از لحاظ اثر تمرين بر سطوح رزيستين

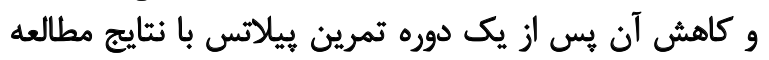

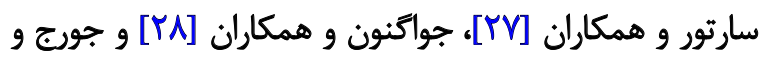

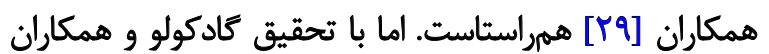

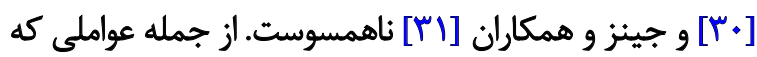

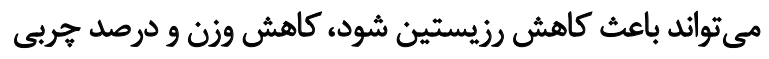

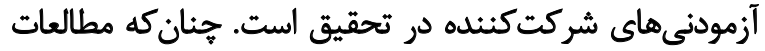

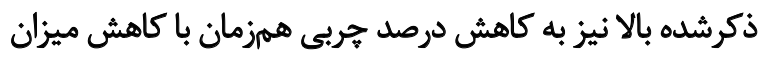

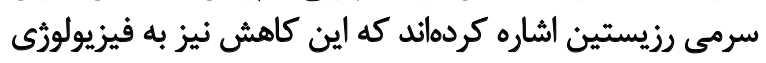

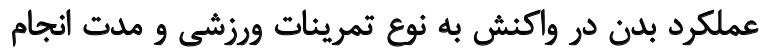

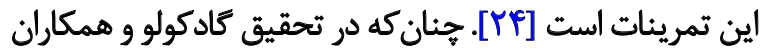

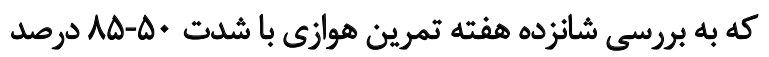

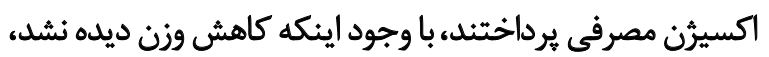

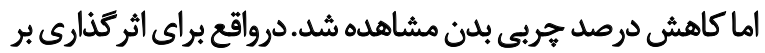

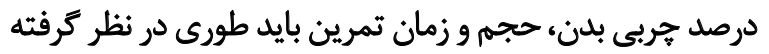

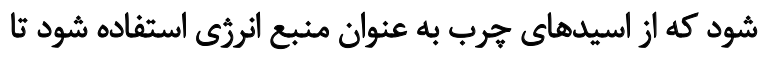

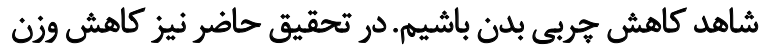

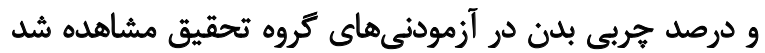

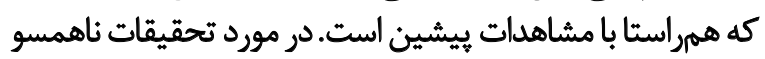

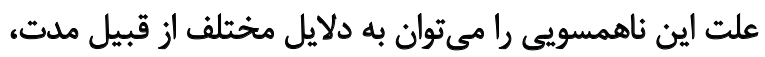

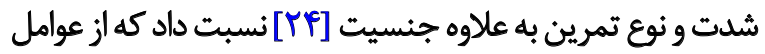

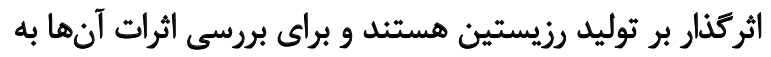
تحقيقات بيشترى نياز است.

از ديكر فاكتورهاى اندازهكيرىشده در بثروهش حاضر

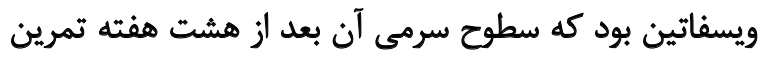

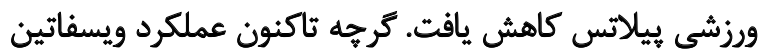

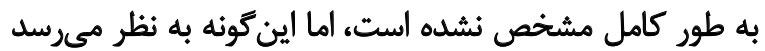

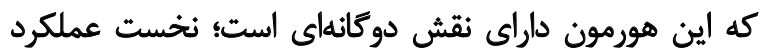

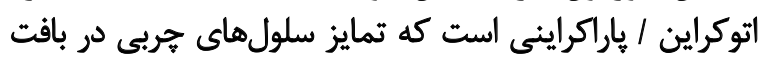

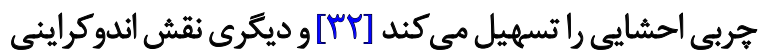




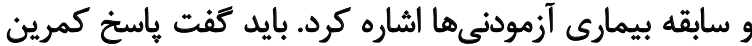

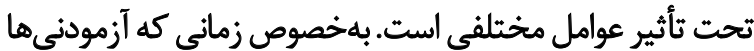

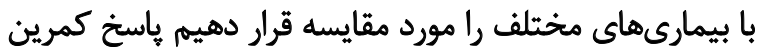

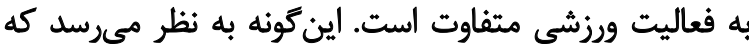

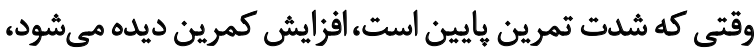

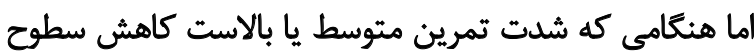

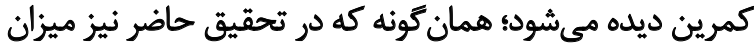
سطوح استراحتى آن كاهش يافته است.

\section{نتيجهي كيرى}

بر اساس نتايج مطالعه حاضر مى ثوان بيان كرد هشت هفته بـانه

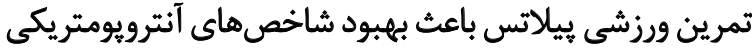

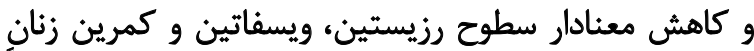

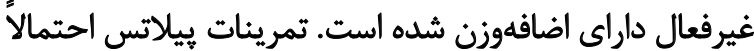

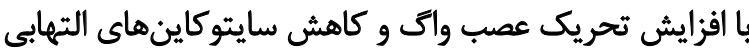

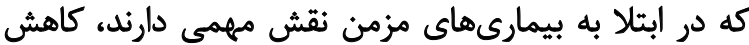

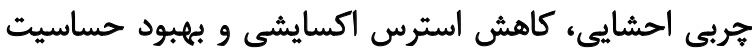

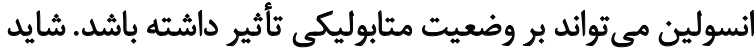

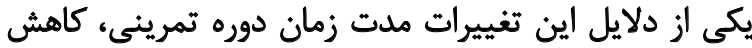

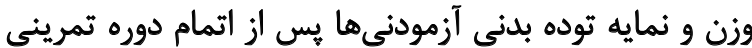

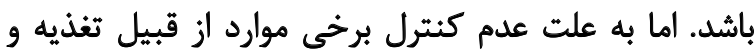

انكيزه آزمودنىها اين نتايح بايد با احتياط تفسير شوند بند

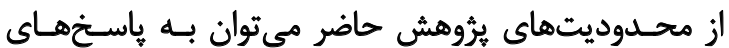

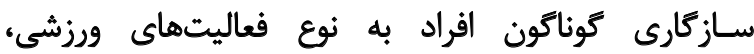

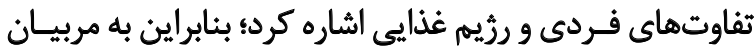

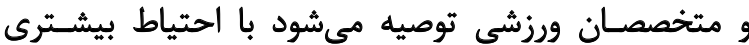
يروتكلـهـاى تمرينى راطراحى كنيند.

مالاحظات اخلاقى

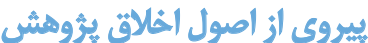

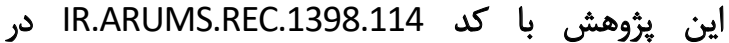

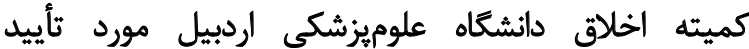
قرار كرفته است و داراي كد كارئ عارئمايى بالينى ارديل به شماره است. RCT20181203037718N1

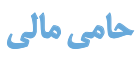

اين مقاله بركرفته از بخشى از طرح يرؤهشى دانشكده علوم

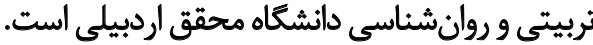

$$
\text { مشاركت ثويسندكان }
$$

نوشتن نسخه اوليه و ايده اصلى: مرده خواجه لندى؛ تأييد و

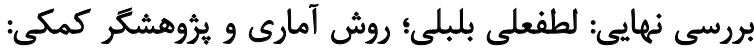

تمرينى انجامشده، نوع آزمـودنىهـا، مدت فعاليت ورزشي،

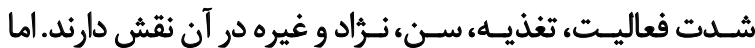

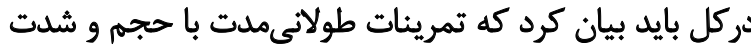

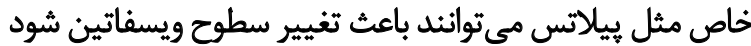

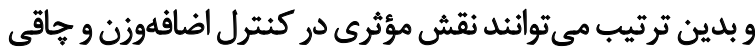

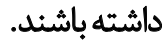

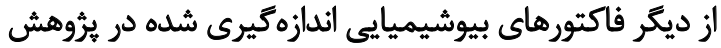

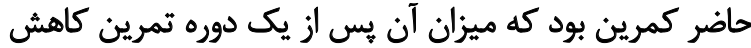

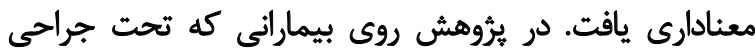

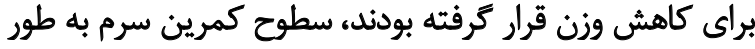

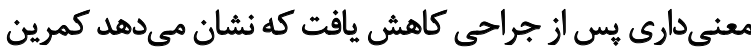

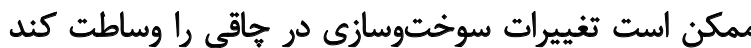

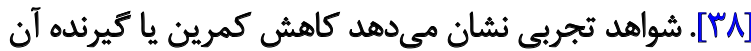

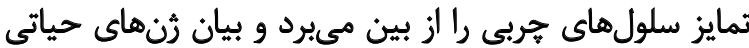

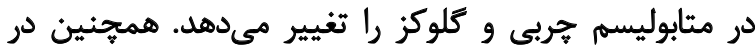

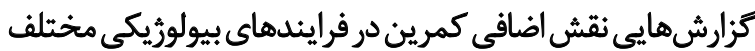

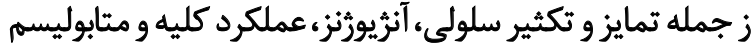

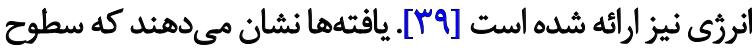

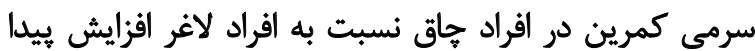

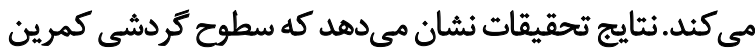

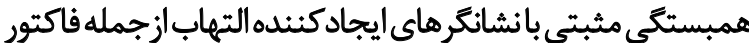

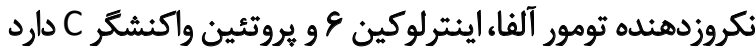

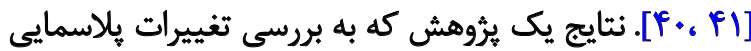

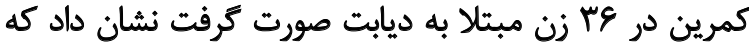

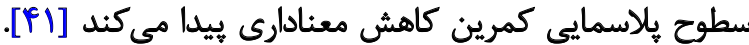

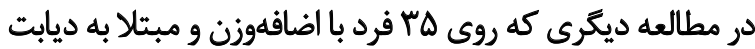

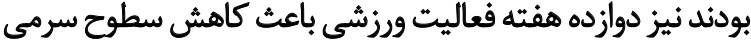

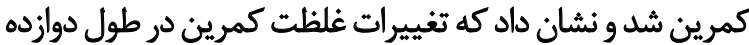

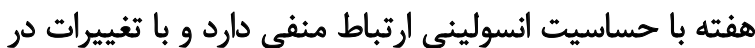

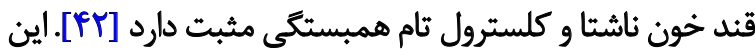

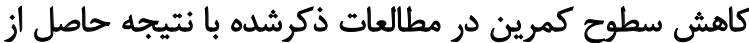

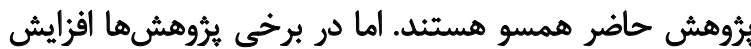

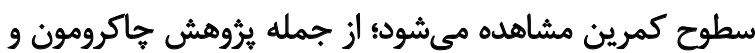

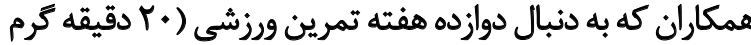

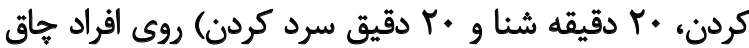

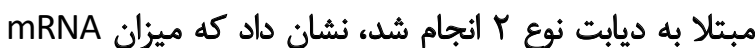

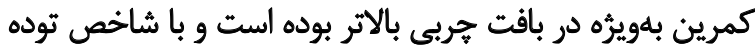

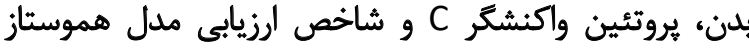

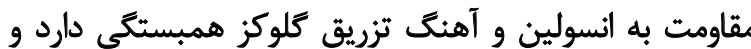

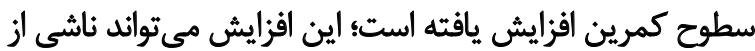

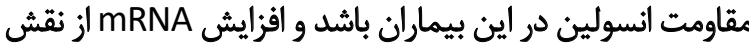

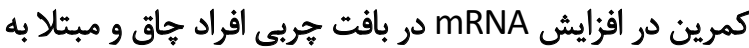

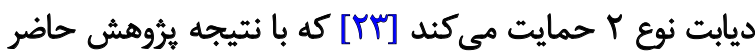

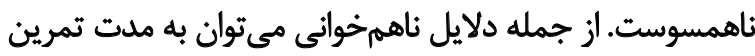


زمستان وqجا. دوره VY. شماره I

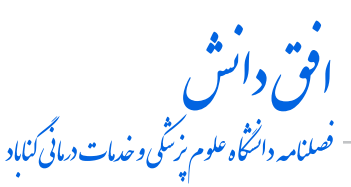

سايه بلبل؛ بحث ونتيجهكيرى: بهزاد ذبيحى. تمعارض مثأق

نويسندكان بيان مى دارند كه هيج كونه تعارض منافعى در اين

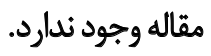

III

هرده خواجه لندى و همكار ان. اثر ييلاتس بر سطوح سرمى برخمى أديبوكاين هاى زئان 


\section{References}

[1] Sánchez-Muñoz C, Muros JJ, Cañas J, Courel-Ibáñez J, Sánchez-Alcaraz BJ, Zabala M. Anthropometric and physical fitness profiles of world-class male padel players. International Journal of Environmental Research and Public Health. 2020; 17(2):508. [DOI:10.3390/ijerph17020508] [PMID] [PMCID]

[2] Konigorski S, Janke J, Drogan D, Bergmann MM, Hierholzer J, Kaaks R, et al. Prediction of circulating adipokine levels based on body fat compartments and adipose tissue gene expression. Obesity Facts. 2019; 12(6):590-605. [DOI:10.1159/000502117] [PMID] [PMCID]

[3] Conde J, Scotece M, Gómez R, López V, Gómez Reino JJ, Lago F, et al. Adipokines: Biofactors from white adipose tissue. A complex hub among inflammation, metabolism, and immunity. BioFactors. 2011; 37(6):41320. [DOI:10.1002/biof.185] [PMID]

[4] Gelsinger C, Tschoner A, Kaser S, Ebenbichler CF. [Adipokine update - new molecules, new functions (German)]. Wiener Medizinische Wochenschrift. 2010; 160(15-16):377-90. [DOI:10.1007/s10354-0100781-6] [PMID]

[5] Aksoy DY, Cinar N, Harmanci A, Karakaya J, Yildiz BO, Usman A, et al. Serum resistin and high sensitive CRP levels in patients with subclinical hypothyroidism before and after L-thyroxine therapy. Medical Science Monitor. 2013; 19:210-5. [DOI:10.12659/MSM.883847] [PMID] [PMCID]

[6] Ding Q, White SP, Ling C, Zhou W. Resistin and cardiovascular disease. Trends in Cardiovascular Medicine. 2011; 21(1):20-7. [DOI:10.1016/j. tcm.2012.01.004] [PMID]

[7] Banerjee RR, Rangwala SM, Shapiro JS, Sophie Rich A, Rhoades B, O $\mathrm{Y}$, et al. Regulation of fasted blood glucose by resistin. Science. 2004; 303(5661):1195-8. [DOI:10.1126/science.1092341] [PMID]

[8] Steppan CM, Bailey ST, Bhat S, Brown EJ, Banerjee RR, Wright CM, et al. The hormone resistin links obesity to diabetes. Nature. 2001; 409:30712. [DOI:10.1038/35053000] [PMID]

[9] Domínguez Coello S, Cabrera de León A, Almeida González D, González Hernández A, Rodríguez Pérez MC, Fernández Ramos N, et al. Inverse association between serum resistin and insulin resistance in humans. Diabetes Research and Clinical Practice. 2008; 82(2):256-61. [DOI:10.1016/j.diabres.2008.08.001] [PMID]

[10] Lee JH, Chan JL, Yiannakouris N, Kontogianni M, Estrada E, Seip R, et al. Circulating resistin levels are not associated with obesity or insulin resistance in humans and are not regulated by fasting or leptin administration: Cross-sectional and interventional studies in normal, insulinresistant, and diabetic subjects. The Journal of Clinical Endocrinology \& Metabolism. 2003; 88(10):4848-56. [DOI:10.1210/jc.2003-030519] [PMID]

[11] Uslu S, Kebapçı N, Kara M, Bal C. Relationship between adipocytokines and cardiovascular risk factors in patients with type 2 diabetes mellitus. Experimental and Therapeutic Medicine. 2012; 4(1):113-20. [DOI:10.3892/etm.2012.557] [PMID] [PMCID]

[12] Pagano C, Pilon C, Olivieri M, Mason P, Fabris R, Serra R, et al. Reduced plasma visfatin/pre-B cell colony-enhancing factor in obesity is not related to insulin resistance in humans. The Journal of Clinical Endocrinology \& Metabolism. 2006; 91(8):3165-70. [DOI:10.1210/jc.2006-0361] [PMID]

[13] Berndt J, Klöting N, Kralisch S, Kovacs P, Fasshauer M, Schön MR, et al. Plasma visfatin concentrations and fat depot-specific mRNA expression in humans. Diabetes. 2005; 54(10):2911-6. [DOI:10.2337/diabetes.54.10.2911] [PMID]
[14] Sun G, Bishop J, Khalili S, Vasdev S, Gill V, Pace D, et al. Serum visfatin concentrations are positively correlated with serum triacylglycerols and down-regulated by overfeeding in healthy young men. The American Journal of Clinical Nutrition. 2007; 85(2):399-404. [DOI:10.1093/ ajcn/85.2.399] [PMID]

[15] Mac Dougald OA, Burant CF. The rapidly expanding family of adipokines Cell Metabolism. 2007; 6(3):159-61. [DOI:10.1016/j.cmet.2007.08.010] [PMID]

[16] Muoio DM, Newgard CB. Obesity-related derangements in metabolic regulation. Annual Review of Biochemistry. 2006; 75:367-401. [DOI:10.1146/annurev.biochem.75.103004.142512] [PMID]

[17] Stejskal D, Karpisek M, Hanulova Z, Svestak M. Chemerin is an independent marker of the metabolic syndrome in a Caucasian populationa pilot study. Biomedical Papers. 2008; 152(2):217-21. [DOI:10.5507/ bp.2008.033] [PMID]

[18] Choi KM, Kim TN, Yoo HJ, Lee KW, Cho GJ, Hwang TG, et al. Effect of exercise training on A-FABP, lipocalin-2 and RBP4 levels in obese women. Clinical Endocrinology. 2009; 70(4):569-74. [DOI:10.1111/j.13652265.2008.03374.x] [PMID]

[19] Venojärvi M, Wasenius N, Manderoos S, Heinonen OJ, Hernelahti M Lindholm H, et al. Nordic walking decreased circulating chemerin and leptin concentrations in middle-aged men with impaired glucose regulation. Annals of Medicine. 2013; 45(2):162-70. [DOI:10.3109/07853890. 2012.727020] [PMID]

[20] Duzova H, Gullu E, Cicek G, Koksal BK, Kayhan B, Gullu A, et al. The effect of exercise induced weight-loss on myokines and adipokines in overweight sedentary females: steps-aerobics vs. jogging-walking exercises. The Journal of Sports Medicine and Physical Fitness. 2018 58(3):295-308. https://www.researchgate.net/profile/Halil-Duezova/ publication/335207140

[21] Lee KJ, Shin YA, Lee KY, Jun TW, Song W. Aerobic exercise training-induced decrease in plasma visfatin and insulin resistance in obese female adolescents. International Journal of Sport Nutrition and Exercise Metabolism. 2010; 20(4):275-81. [DOI:10.1123/ijsnem.20.4.275] [PMID]

[22] Bo S, Ciccone G, Baldi I, Gambino R, Mandrile C, Durazzo M, et al. Plasma visfatin concentrations after a lifestyle intervention were directly associated with inflammatory markers. Nutrition, Metabolism and Cardiovascular Diseases. 2009; 19(6):423-30. [DOI:10.1016/j.numecd.2008.09.001] [PMID]

[23] Chakaroun R, Raschpichler M, Klöting N, Oberbach A, Flehmig G, Kern $M$, et al. Effects of weight loss and exercise on chemerin serum concentrations and adipose tissue expression in human obesity. Metabolism. 2012; 61(5):706-14. [DOI:10.1016/j.metabol.2011.10.008] [PMID]

[24] Khajehlandi M, Bolboli L, Siahkuhian M, Nikseresht F. [Effect of 12 weeks of Pilates training on the serum levels of interleukin-6, C - reactive protein and tumor nerosis factor- $\alpha$ in inactive overweight women (Persian)]. Medical Journal of Tabriz University of Medical Sciences and Health Services. 2020; 42(1):56-64. [DOI:10.34172/mj.2020.020]

[25] Deng Y, Scherer PE. Adipokines as novel biomarkers and regulators of the metabolic syndrome. Annals of the New York Academy of Sciences. 2010; 1212(1):E1-19. [DOI:10.1111/j.1749-6632.2010.05875.x] [PMID] [PMCID]

[26] Balducci S, Zanuso S, Nicolucci A, Fernando F, Cavallo S, Cardelli P, et al. Anti-inflammatory effect of exercise training in subjects with type 2 diabetes and the metabolic syndrome is dependent on exercise modalities and independent of weight loss. Nutrition, Metabolism and Cardiovascular Diseases. 2010; 20(8):608-17. [DOI:10.1016/j.numecd.2009.04.015] [PMID] 
[27] Sartor F, de Morree HM, Matschke V, Marcora SM, Milousis A, Thom $J M$, et al. High-intensity exercise and carbohydrate-reduced energy-restricted diet in obese individuals. European Journal of Applied Physiology. 2010; 110(5):893-903. [DOI:10.1007/s00421-010-1571-y] [PMID]

[28] Gueugnon C, Mougin F, Simon-Rigaud ML, Regnard J, Nègre V, Dumoulin $\mathrm{G}$. Effects of an in-patient treatment program based on regular exercise and a balanced diet on high molecular weight adiponectin, resistin levels, and insulin resistance in adolescents with severe obesity. Applied Physiology, Nutrition, and Metabolism. 2012; 37(4):672-9. [DOI:10.1139/h2012-045] [PMID]

[29] Jorge MLMP, de Oliveira VN, Resende NM, Paraiso LF, Calixto A, Diniz ALD, et al. The effects of aerobic, resistance, and combined exercise on metabolic control, inflammatory markers, adipocytokines, and muscle insulin signaling in patients with type 2 diabetes mellitus. Metabolism. 2011; 60(9):1244-52. [DOI:10.1016/j.metabol.2011.01.006] [PMID]

[30] Jones TE, Basilio JL, Brophy PM, McCammon MR, Hickner RC. Longterm exercise training in overweight adolescents improves plasma peptide YY and resistin. Obesity. 2009; 17(6):1189-95. [DOI:10.1038/ oby.2009.11] [PMID] [PMCID]

[31] Kang J, Robertson RJ, Hagberg JM, Kelley DE, Goss FL, Dasilva SG, et al. Effect of exercise intensity on glucose, and insulin metabolism in obese individuals and obese NIDDM patients. Diabetes Care. 1996; 19(4):3419. [DOI:10.2337/diacare.19.4.341] [PMID]

[32] El-Mesallamy HO, Kassem DH, El-Demerdash E, Amin Al. Vaspin and visfatin/Nampt are interesting interrelated adipokines playing a role in the pathogenesis of type 2 diabetes mellitus. Metabolism: Clinical and Experimental. 2011; 60(1):63-70. [DOI:10.1016/j.metabol.2010.04.008] [PMID]

[33] Soltani F, Daryanoosh F, Salesi M, Mohamadi M, Jafari H, Soltani A. [The effect of eight weeks of aerobic exercises on visfatin, IL- 6 and TNF- $\alpha$ in female Sprague Dawley Rats (Persian)]. Journal of Advances in Medical and Biomedical Research. 2013; 21(89):30-9. http://zums.ac.ir/ journal/article-1-2400-en.html

[34] Haider DG, Schindler K, Schaller G, Prager G, Wolzt M, Ludvik B. Increased plasma visfatin concentrations in morbidly obese subjects are reduced after gastric banding. The Journal of Clinical Endocrinology \& Metabolism. 2006; 91(4):1578-81. [DOI:10.1210/jc.2005-2248] [PMID]

[35] Mohammadi Domieh A, Khajehlandi A. Effect of 8 weeks endurance training on plasma visfatin in middle-aged men. Brazilian Journal of Biomotricity. 2010; 4(3):174-9. https://www.redalyc.org/articulo. oa?id=93021660004

[36] Choi KM, Kim JH, Cho GJ, Baik SH, Park HS, Kim SM. Effect of exercise training on plasma visfatin and eotaxin levels. European Journal of Endocrinology. 2007; 157(4):437-42. [DOI:10.1530/EJE-07-0127] [PMID]

[37] Taghian F, Zolfaghary M, Hedayati M. [Effect of 12 weeks aerobic exercise on visfatin level and insulin resistance in obese women (Persian)]. Razi Journal of Medical Sciences. 2014; 20(116):35-44. http://rjms.iums. ac.ir/article-1-2943-en.html

[38] Sell H, Divoux A, Poitou C, Basdevant A, Bouillot JL, Bedossa P, et al. Chemerin correlates with markers for fatty liver in morbidly obese patients and strongly decreases after weight loss induced by bariatric surgery. The Journal of Clinical Endocrinology \& Metabolism. 2010; 95(6):2892-6. [DOI:10.1210/jc.2009-2374] [PMID]

[39] Ernst MC, Sinal CJ. Chemerin: At the crossroads of inflammation and obesity. Trends in Endocrinology \& Metabolism. 2010; 21(11):660-7. [DOI:10.1016/j.tem.2010.08.001] [PMID]

[40] Parlee SD, Ernst MC, Muruganandan Sh, Sinal CJ, Goralski KB. Serum chemerin levels vary with time of day and are modified by obesity and tumor necrosis factor- $\alpha$. Endocrinology. 2010; 151(6):2590-602. [DOI:10.1210/en.2009-0794] [PMID]

[41] Lloyd JW, Evans KA, Zerfass KM, Holmstrup ME, Kanaley JA, Keslacy S. Effect of an acute bout of aerobic exercise on chemerin levels in obese adults. Diabetes \& Metabolic Syndrome: Clinical Research \& Reviews. 2016; 10(1):37-42. [DOI:10.1016/j.dsx.2015.04.010] [PMID] [PMCID]

[42] Kim SH, Lee SH, Ahn KY, Lee DH, Suh YJ, Cho SG, et al. Effect of lifestyle modification on serum chemerin concentration and its association with insulin sensitivity in overweight and obese adults with type 2 diabetes. Clinical Endocrinology. 2014; 80(6):825-33. [DOI:10.1111/cen.12249] [PMID] 